\title{
SUBSTRATE SPECIFICITY OF PROTEINASE YSCA FROM SACCHAROMYCES CEREVISIAE
}

\author{
by \\ THOMAS DREYER \\ Department of Chemistry, Carlsberg Laboratory, \\ Gamle Carlsberg Vej 10, DK-2500 Copenhagen Valby
}

Keywords: Aspartic proteinase, proteinase yscA, specificity, Saccharomyces cerevisiae, yeast

Proteinase yscA is an intracellular aspartic proteinase located in the lysosome-like vacuole of the yeast cell. The specificity towards denatured protein substrates was determined by separation and identification of cleavage products after digestions with proteinase ysc $\mathrm{A}$, and compared to that obtained with pepsin used under similar conditions. Proteinase yscA is more selective towards the peptide bonds it cleaves than pepsin, but shows the same preference for large hydrophobic residues on both sides of the cleaved bond as pepsin and lysosomal cathepsin $D$. Phe, Leu and Glu are favoured in substrate subsite $\mathbf{P}_{1}$ and Phe, Ile, Leu and Ala in $\mathbf{P}_{1}^{\prime}$, whereas Val is unfavoured in $P_{1}^{\prime}$. The implications for the role of proteinase yscA as hydrolase maturase are discussed.

\section{INTRODUCTION}

Proteinase yscA is a proteolytic enzyme belonging to the aspartic proteinase family. It is located in the vacuole of the yeast Saccharomyces cerevisiae, together with several other hydrolases including two carboxypeptidases, yscY and yscS, a subtilisin-like proteinase yscB, two aminopeptidases, yscI and yscCo, several phosphatases and a ribonuclease (for review; see ref. 28). The vacuoles of plant cells and fungi share several biochemical and functional features with the lysosomes of the animal cell (18).

Vacuolar aspartic proteinases from fungi and yeasts are not well characterized, in spite of the increasing interest in yeast as a model system for investigations of eucaryotic cell metabolism. Hence, it was found interesting to analyze the substrate specificity of proteinase yscA from Saccharomyces cerevisiae.

The primary structure of this proteinase is related to the mammalian aspartic proteinases; with regard to amino acid sequence proteinase yscA is $46 \%$ identical with porcine lysosomal cathepsin D and $40 \%$ identical with porcine pepsin (6). Furthermore, cathepsin D and proteinases yscA both have two carbohydrate attachment sites, one of which is in the same position in the two molecules $(6,27)$. These

Abbreviations: FA = furylacryloyl; LHRH = luteinizing hormone-releasing hormone; RP-HPLC $=$ reverse phase high performance liquid chromatography; SDS-PAGE = sodium dodecyl sulfate polyacrylamide gel electrophoresis; TFA = trifluoroacetic acid.

Abbreviations of amino acids are according to the guidelines of the IUPAC-IUB Commission on Biochemical Nomenclature. The binding site notations for enzymes and substrates are those of SCHECHTER and BERGER (26). Accordingly, the amino acid residues in the amino-terminal direction away from the scissile bond of the substrate are denoted $\mathbf{P}_{1}, \mathbf{P}_{2}, \ldots ., \mathbf{P}_{\mathbf{n}}$ and in the carboxy-terminal direction $\mathbf{P}_{1}^{\prime}, \mathbf{P}_{2}^{\prime}, \ldots ., \mathbf{P}_{\mathbf{n}}^{\prime}$. 
structural parallels are consistent with the close relationship between the biochemistry of the lysosomes and vacuoles. In the present study the actions of highly purified proteinase yscA were investigated on unfolded myoglobin, insulin Aand B-chains and ribonuclease, together with the peptides angiotensin II, luteinizing hormone-releasing hormone (LHRH) and substance $\mathrm{P}$ and its derivatives.

The results show that proteinase yscA degrades myoglobin at a rate similar to pepsin, though insulin B-chain and oxidized ribonuclease are degraded slower by proteinase yscA than by pepsin. The different extents of hydrolysis reveal that proteinase yscA has a more limited substrate specificity than porcine pepsin. The cleavage pattern of the tested substrates resembles that earlier reported for cathepsin $D$, extending the previously established relationship between these two enzymes $(6,27)$.

\section{MATERIALS}

Proteinase yscA from Saccharomyces cerevisiae was obtained by the purification procedure described in reference 6 . The resulting preparation was homogenous as judged by SDSPAGE, and it contained no measurable carboxypeptidase activity, when assayed with the substrate FA-Phe-Leu (4). The molar amount of active enzyme in the preparation was established by titration with the inhibitor pepstatin, using the chromophoric peptide substrate Lys-Pro-Ile-Glu-Phe-( $\left.\mathrm{NO}_{2}\right)$ Phe-Arg-Leu, kindly supplied by B.M. DUNN (8). Subsequent protein determination by amino acid analysis showed that $95 \% \pm 5 \%$ of the enzyme was active, based on a molecular weight of 41,500 (6). The activity of proteinase yscA was partially lost during lyophilization, but the enzyme was stable when frozen at $-20^{\circ} \mathrm{C}$ in $0.05 \mathrm{M}$ ammonium acetate, $\mathrm{pH} 5.0$ in a concentration of $4-20$ $\mathrm{mg} / \mathrm{ml}$. Since diluted solutions were relatively unstable, freshly prepared solutions were used for each digestion experiment.

Pepsin and the substrates sperm whale myoglobin, bovine ribonuclease, bovine insulin, human angiotensin II, human substance $\mathbf{P}$, substance $P\left(\mathrm{Tyr}^{8}\right)$ and substance $P(6-11)$ were purchased from Sigma, USA. Human LHRH was a kind gift from Carlbiotech, Denmark. The concentration of pepsin was determined as described above for proteinase yscA. The protein substrates were denatured either by acid treatment (myoglobin) or by performic acid oxidation (5) (insulin and ribonucleases) in order to minimize effects of secondary and tertiary structure. The oxidized A- and B-chains of insulin were separated by gel filtration on BioGel P30 in $50 \%(\mathrm{v} / \mathrm{v})$ acetic acid, $4{ }^{\circ} \mathrm{C}$, and subsequently lyophilized. All other reagents used were analytical grade.

\section{METHODS}

\subsection{Digestion of substrates}

The digestions of protein and peptide substrates with proteinase yscA were normally performed in $0.05 \mathrm{M}$ ammonium formiate $\mathrm{pH} 3.20$ at $22^{\circ} \mathrm{C}$ or $37^{\circ} \mathrm{C}$. The reaction was initiated by addition of an aliquot of a freshly diluted proteinase yscA solution $(0.4 \mathrm{mg} / \mathrm{ml})$ to $2.5 \mathrm{ml}$ thermostated substrate solution. Substrate concentrations ranged from $0.2 \mathrm{mg} / \mathrm{ml}$ to $4 \mathrm{mg} / \mathrm{ml}$ and enzyme to substrate (E/S) ratios between $1 / 235(\mathrm{~mol} / \mathrm{mol})$ and $1 / 23,500(\mathrm{~mol} / \mathrm{mol})$ were used for the various substrates. All the following $\mathrm{E} / \mathrm{S}$-ratio's are given in $\mathrm{mol} / \mathrm{mol} .500 \mu \mathrm{l}$ aliquots were withdrawn at regular intervals ranging from $2 \mathrm{~min}$ to 24 hours. The reaction was stopped by heating in a boiling water bath for 2 min, or by increasing $\mathrm{pH}$ to 9.0 with ammonium hydroxide. While proteinase yscA is stable for more than two hours at $\mathrm{pH} 7.6,20^{\circ} \mathrm{C}$, it is rapidly and irreversibly inactivated above $\mathrm{pH}$ 8.0 (results not shown). The samples were frozen or lyophilized. Digestions of myoglobin and oxidized ribonuclease with pepsin were similarly performed in $0.05 \mathrm{M}$ ammonium formiate buffer, but at $\mathrm{pH} 2.5$ where this enzyme is more active. Otherwise the methodology followed the above description for proteinase yscA. Occasionally $3 \mathrm{M}$ urea was included in the substrate solutions. In these cases $\mathrm{pH}$ was increased to 4.0 in order to protect proteinase yscA from the denaturing effect of urea at low $\mathrm{pH}$.

\subsection{Separation of peptides}

Separation of the hydrolysis products was accomplished by high-performance liquid chro- 
matography (HPLC) employing Waters HPLCequipment, as described in reference 6 . Solvents used for elution of peptides consisted of $0.1 \%$ TFA and gradients were generated with increasing concentrations of acetonitril or n-propanol. Different reverse-phase column materials were employed: Novapak C-18 (Waters Inc., USA), Synchropak wide-pore RP-P (SynChrom Inc., USA) and Vydac wide-pore C-18 (HPLC Technology Ltd., UK). Some peptides co-eluted in the first separation, and rechromatography of the collected fused peaks with different eluent and/or column material was frequently necessary to obtain peptides sufficiently pure for unambigous identification. The eluents were monitored at $225 \mathrm{~nm}$ and $280 \mathrm{~nm}$ using a Waters Model 490 detector, recording the former absorption and the ratio. Myoglobin peptides were additionally monitored fluorometrically using a Model 420 fluorescense detector, in order to assign tryptophan containing peptides.

\subsection{Analysis of isolated peptides}

Peptides were quantified and identified by amino acid analysis on a Durrum D-500 amino acid analyzer. In most cases $\mathrm{N}$-terminal sequencing on either a Beckman $890 \mathrm{C}$ spinning cup sequencer for long peptides or an Applied Biosystems gas phase sequencer Model 470A for peptides of small size or in low yield, was used to confirm the identification.

The rates of hydrolysis of different peptide bonds reported here varied widely. Slow cleavages, at rates lower than approx. 1/100 of the highest rates, were disregarded due to the risk of interference from trace amounts of foreign proteases in pepsin or proteinase yscA preparations.

\subsection{Kinetic methods}

In order to assess the catalytic efficiency of proteinase yscA towards the most labile peptide bond in myoglobin and to compare it with pepsin, rates of hydrolysis of myoglobin were measured as the decrease in peak hight following HPLC-separation of aliquots withdrawn during the initial stage of hydrolysis at different substrate concentrations. Hydrolysis rates were ob- tained at four substrate concentrations for proteinase yscA: $29 \mu \mathrm{M}, 58 \mu \mathrm{M}, 120 \mu \mathrm{M}$, and 230 $\mu \mathrm{M}$ (single determinations) and two substrate concentrations for pepsin: $47 \mu \mathrm{M}$ and $93 \mu \mathrm{M}$ (duplicate determinations). Rais: were measured as mol myoglobin hydrolyzed per second in $1 \mathrm{ml}$ with $1 \mathrm{nM}$ enzyme, based on molecular weights of 41,500 (proteinase yscA) and 35,000 (porcine pepsin). The Michälis-Menten parameters, $K_{m}$ and $k_{\text {cal }}$, together with specificity constants, $k_{\text {cat }} / K_{m}$, were estimated from intercepts and slopes of double-reciprocal plots of rates vs. substrate concentrations.

\section{RESULTS}

\subsection{Hydrolysis of unfolded protein substrates}

Proteinase yscA had very different effects on the denatured protein substrates myoglobin, oxidized ribonuclease and oxidized insulin Aand B-chains. Insulin A-chain proved to be highly resistant to proteinase yscA, since no hydrolysis was detected in samples withdrawn after $300 \mathrm{~min}$ of digestion at E/S-ratio 1/1,700. In this respect proteinase yscA differs from rat liver cathepsin $D$, which cleaves the A-chain at $\mathrm{Glu}^{17}-\mathrm{Asn}^{18}$ (13). The oxidized B-chain was, however, readily digested, initially producing two fragments. Oxidized ribonuclease was not fully digested even after 24 hours hydrolysis at E/S-ratio 1/1,400. Acid denatured myoglobin proved to be an excellent substrate which was completely degraded at E/S-ratio 1/23,500 after only 10 minutes.

\subsubsection{Hydrolysis of acid denatured sperm whale myoglobin.}

The first peptide bonds to be hydrolyzed in myoglobin were $\mathrm{Leu}^{29}-\mathrm{Ile}^{30}$ and Leu ${ }^{32}-\mathrm{Phe}^{33}$. Figure 1a shows the peptide composition after 5 min of hydrolysis at E/S-ratio 1/11,750. Comparable amounts of amino acids were liberated from the peptides $\mathrm{Ile}^{30}-\mathrm{Gly}^{153}$ and $\mathrm{Phe}^{33}$-Gly ${ }^{153}$ during Edman degradation on the Beckman-sequencer of the fused peak from HPLC. The peptide $\mathrm{Ile}^{30}-\mathrm{Arg}^{31}-\mathrm{Leu}^{32}$ was eluted in the front peak with the chromatographic conditions employed, but peptide $\mathrm{Val}^{1}$-Leu ${ }^{32}$ was never isolated, suggesting that cleavage in myoglobin of Leu $^{32}-$ Phe $^{33}$ occurs subsequent to the removal of 
T. DREYER: Specificity of proteinase yscA
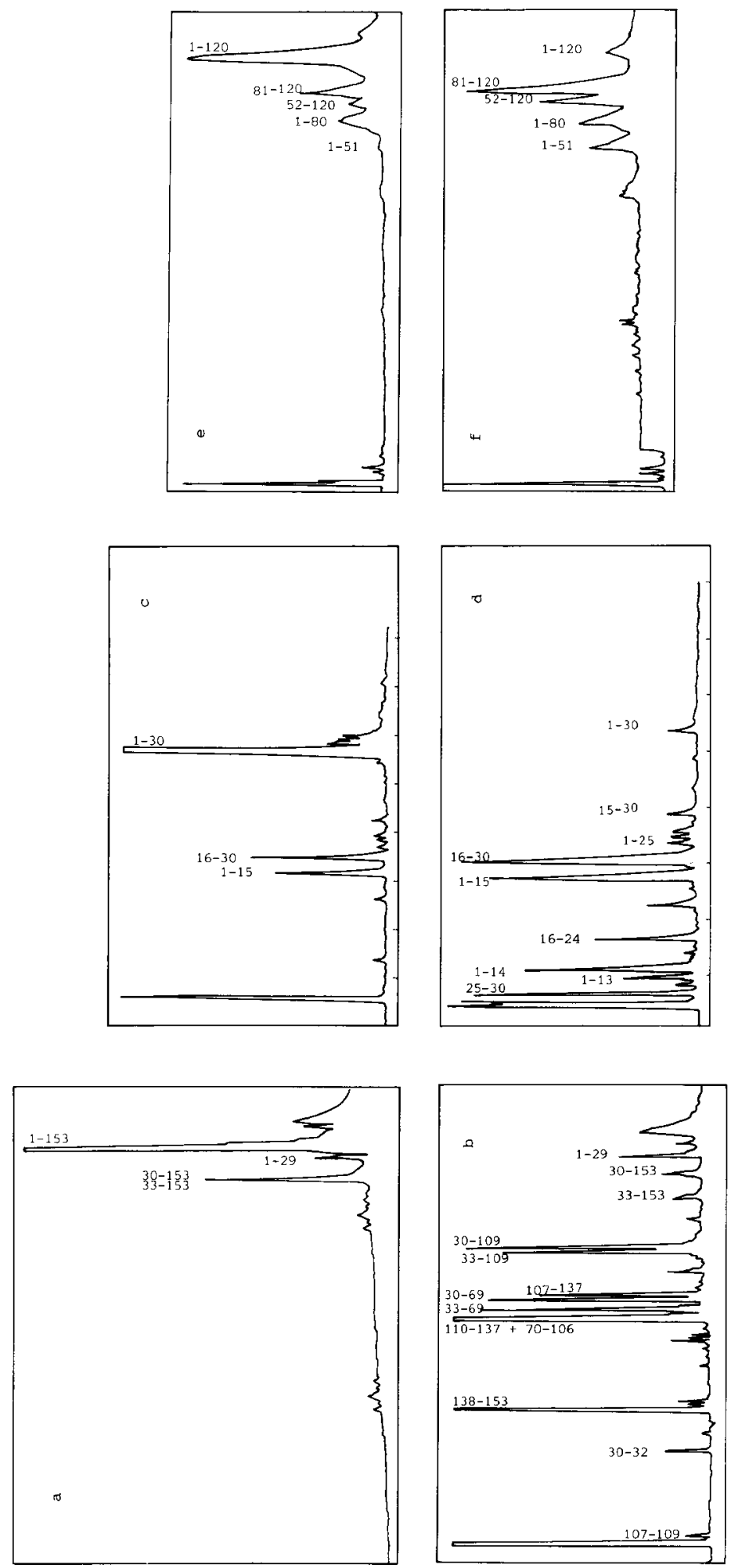

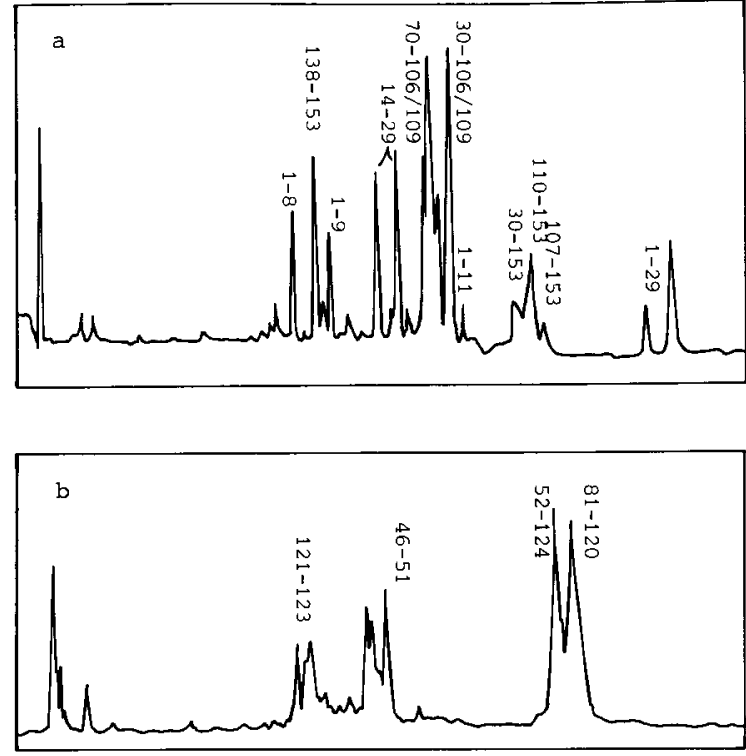

Figure 2. RP-HPLC chromatograms of peptide mixtures resulting from digestion of myoglobin (a) and ox. ribonuclease (b) with porcine pepsin. The chromatographic conditions were the same as described in Figure 1 for myoglobin and ox. ribonuclease, respectively.

$\mathrm{Val}^{1}-\mathrm{Leu}^{29}$. However, as large peptides resulting from the initial cleavages proved difficult to separate efficiently, it cannot be ruled out that small amounts of $\mathrm{Val}^{1}$ - $\mathrm{Leu}^{32}$ is eluted under the myoglobin peak during separations corresponding to early stages of hydrolysis, even though amino acid analysis of the myoglobin peak gave no indication of significant contamination. The peptide $\mathrm{Val}^{1}-\mathrm{Leu}^{29}$ is very hydrophobic and late eluting from RP-HPLC columns, and recoveries varied between $0 \%$ and $40 \%$, depending on the sample treatment before analysis. The higest recovery was obtained when $3 \mathrm{M}$ urea was included in the myoglobin solution during digestion. Urea apparently prevents precipitation or agglomeration of this peptide during heating or freezing/thawing. Figure $1 \mathrm{~b}$ shows the peptide composition after 60 min hydrolysis at $\mathrm{E} / \mathrm{S}$-ratio $1 / 2,350$. At this point considerable cleavage of four more peptide bonds was evident: $\mathrm{Glu}^{109}$. $\mathrm{Ala}^{110}$, Leu ${ }^{137}-\mathrm{Phe}^{138}$, Leu ${ }^{69}-\mathrm{Thr}^{70}$ and $\mathrm{Phe}^{106}$ $\mathrm{Ile}^{107}$. Further hydrolysis produced several smaller fragments derived from slow cleavages in the N-terminal region: $\mathrm{Leu}^{2}-\mathrm{Ser}^{3}, \mathrm{Gln}^{8}-\mathrm{Leu}^{9}$, $\mathrm{Leu}^{11}-\mathrm{His}^{12}, \operatorname{Tr}^{7}-\mathrm{Gln}^{8}$ and also $\mathrm{Ala}^{134}-\mathrm{Leu}^{135}$.

Pepsin was shown to cleave almost the same peptide bonds in myoglobin as proteinase yscA, although $\mathrm{Leu}^{32}-\mathrm{Phe}^{33}$ was apparently not susceptible to hydrolysis. In addition, the hydrophobic $\mathrm{N}$-terminal region was more extensively hydrolyzed by pepsin due to cleavage of Leu'- Val ${ }^{10}$ and $\mathrm{Val}^{13}-\mathrm{Trp}^{14}$. Figure 2a shows the fractionation of peptides from digestion with pepsin for $60 \mathrm{~min}$ at E/S-ratio 1/2,350. Rat liver cathepsin $\mathrm{D}$ is reported by IMOTo et al. (13) to cleave denatured myoglobin in the same positions as shown here for proteinase yscA, except for position $\mathrm{Glu}^{109}-\mathrm{Ala}^{110}$. Cathepsin D is claimed to cleave $\mathrm{Ala}^{110}-\mathrm{Ile}^{111}$ instead (see Discussion). Small deviations between proteinase yscA and cathepsin D specificities are observed towards slowly hydrolyzed peptide bonds in the N-terminal region of myoglobin. Figure 3 summarizes the comparison of specificities towards myoglobin.

\subsubsection{Hydrolysis of the B-chain of oxidized bovine insulin}

The B-chain of oxidized insulin was initially cleaved only at Leu ${ }^{15}-\mathrm{Tyr}^{16}$ (Fig. 1c). When the E/S-ratio was increased five-fold from $1 / 57,000$ to $1 / 11,400$ and the incubation time doubled from 30 to $60 \mathrm{~min}$, cleavage was also obtained at $\mathrm{Phe}^{24}-\mathrm{Phe}^{25}, \mathrm{Ala}^{14}-\mathrm{Leu}^{15}$, Glu ${ }^{13}-\mathrm{Ala}^{14}$ and $\mathrm{Tyr}^{26}$ $\mathrm{Thr}^{27}$ (Fig. 1d). Pepsin has been reported to cleave this substrate primarily at $\mathrm{Tyr}^{16}-\mathrm{Leu}^{17}$, $\mathrm{Leu}^{11}-\mathrm{Val}^{12}$ and $\mathrm{Phe}^{25}-\mathrm{Tyr}^{26}$ (25) which are not cleaved by proteinase yscA, and at $\mathrm{Phe}^{24}-\mathrm{Phe}^{25}$.

Figure 1. RP-HPLC chromatograms of peptide mixtures resulting from initial (upper row) and extensive (lower row) digestion of myoglobin $(a, b)$, ox. insulin B-chain $(c, d)$ and ox. ribonuclease $(e, f)$ with proteinase yscA. Peptides were eluted from a Vydac C-18 column (panels a-d) or a Novapak C-18 column (panels e-f) by generating linear gradients of acetonitril in $0.1 \% \mathrm{TFA}, 1 \mathrm{ml} / \mathrm{min}$, in panels a and b: $9 \%-54 \%$ acetonitril in $80 \mathrm{~min}$, in panels $\mathrm{c}$ and d: $18 \%-41 \%$ acetonitril in $50 \mathrm{~min}$ and in panels e and f: $9 \%-50 \%$ acetonitril in $80 \mathrm{~min}$. 


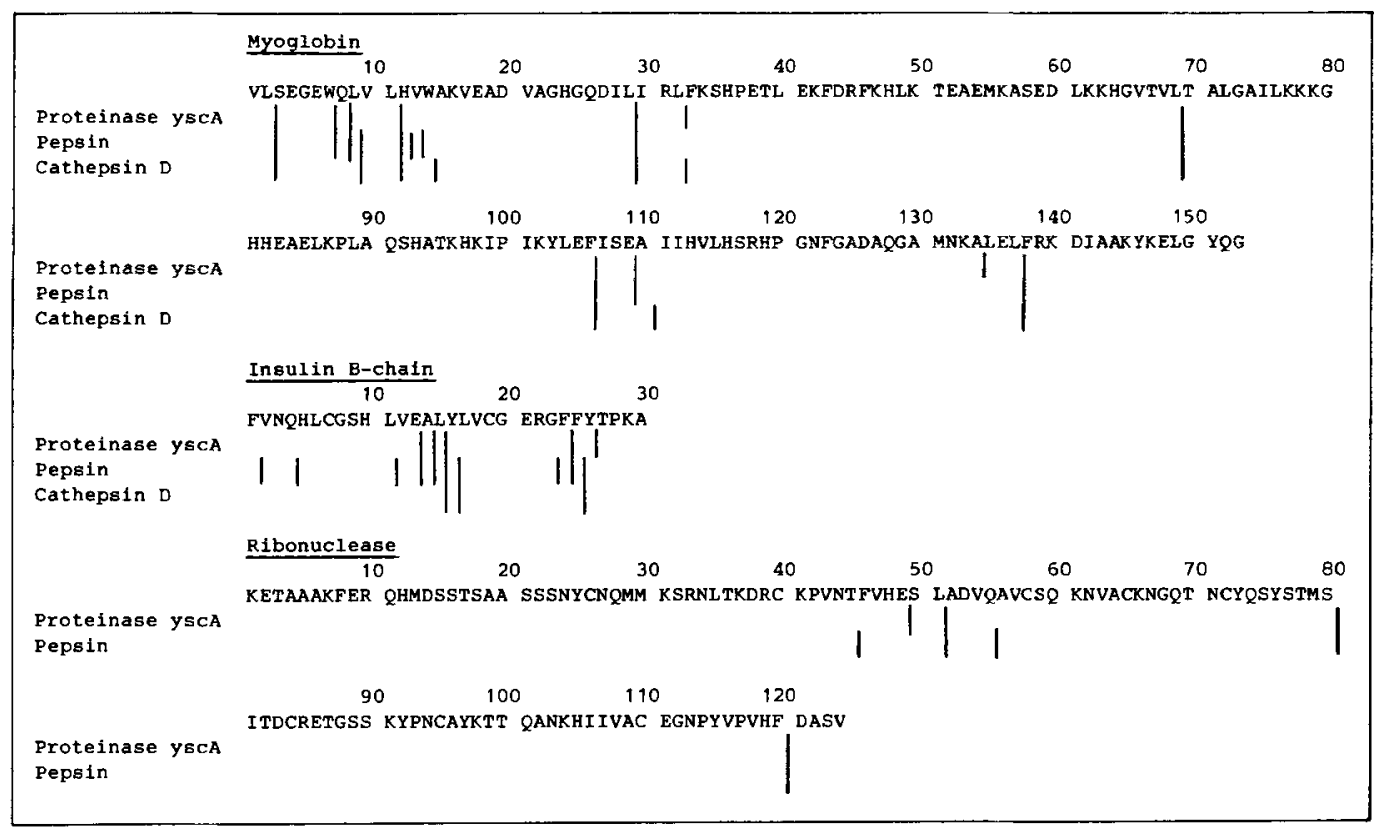

Figure 3. Cleavage sites in denatured protein substrates after hydrolysis with proteinase yscA, porcine pepsin and rat liver cathepsin $\mathrm{D}(6,13,27,29)$.

Secondary cleavages occur at $\mathrm{Glu}^{13}-\mathrm{Ala}^{14}, \mathrm{Ala}^{14}$ Leu $^{15}$ and Leu ${ }^{15}-\mathrm{Tyr}^{16}$, in addition to three peptide bonds left untouched by proteinase yscA: Gly ${ }^{23}-\mathrm{Phe}^{24}, \mathrm{Phe}^{1}-\mathrm{Val}^{2}$ and $\mathrm{Gln}^{4}-\mathrm{His}^{5}$. The close similarity in the specificity of proteinase ysc A and cathepsin D towards myoglobin is not mirrored in the insulin B-chain, as seen from Figure 3. Cathepsin D cleaves $\mathrm{Tyr}^{16}-\mathrm{Leu}^{17}$ and $\mathrm{Phe}^{25}-\mathrm{Tyr}^{26}$, like pepsin, in addition to $\mathrm{Leu}^{15}$. $\operatorname{Tyr}^{16}$ (13).

\subsubsection{Hydrolysis of oxidized bovine ribonuclease}

Oxidized ribonuclease was digested slowly by proteinase yscA even at a high E/S-ratio of $1 / 1,430$ to yield four peptides (Fig. 1e). The cleaved peptide bonds were: $\mathrm{Leu}^{51}-\mathrm{Ala}^{52}, \mathrm{Ser}^{80}$ $\mathrm{Ile}^{81}$ and $\mathrm{Phe}^{120}$-Asp ${ }^{121}$. After prolonged incubation (24 hours) the HPLC-peak corresponding to the peptide Lys ${ }^{1}$-Leu ${ }^{51}$ broadened (Fig. 1f). This is probably due to contamination with the peptide Lys ${ }^{1}-\mathrm{Glu}^{49}$, as sequencing of the mixture of peptides after digestion, but before separation, indicated the presence of a peptide with
$\mathrm{N}$-terminal sequence Ser-Leu-Ala-, as evidence of slow cleavage of the peptide bond $\mathrm{Glu}^{49}-\mathrm{Ser}^{50}$.

Pepsin similarly cleaved oxidized ribonuclease at $\mathrm{Leu}^{51}-\mathrm{Ala}^{52}, \mathrm{Phe}^{120}-\mathrm{Asp}^{121}$ and $\mathrm{Ser}^{80}-\mathrm{Ile}^{81}$, but additionally at $\mathrm{Thr}^{45}-\mathrm{Phe}^{46}$ and $\mathrm{Gln}^{55}-\mathrm{Ala}^{56}$ (Fig. 2b and Fig. 3). Glu ${ }^{49}-\operatorname{Ser}^{50}$, cleaved by proteinase yscA, was apparently resistant to the action of pepsin.

No data were found in the literature on the hydrolysis of this substrate by cathepsin $D$.

\subsubsection{Kinetics of hydrolysis of myoglobin}

Table I gives estimates of the MichälisMenten parameters and specificity constants for the digestion of myoglobin with proteinase yscA and pepsin at $\mathrm{pH} 3.20$ and $\mathrm{pH} 2.50$, respectively, in $0.05 \mathrm{M}$ ammonium formiate, $37^{\circ} \mathrm{C}$. Initial hydrolysis rates of the $\mathrm{Leu}^{29}-\mathrm{Il}^{30}$ peptide bond were obtained at the substrate concentrations described in section 3.4. The differences in kinetic parameters obtained with the present two datasets for proteinase yscA and pepsin are not statistically significant. 


\subsection{Hydrolysis of peptide substrates}

Small synthetic substrates with systematic variations in subsite side chains, developed and used for the characterization of pepsin specificity (9), were either cleaved too slowly or not at all by proteinase yscA (results not shown). Chromophoric octapeptide substrates, designed according to established pepsin subsite specificity by DUNN et al. (8) are cleaved by proteinase yscA between two phenylalanines. The enzyme appears, however, to be among the least active towards this class of substrates, with kinetic constants close to those of bovine cathepsin D and chymosin (7).

Pharmacologically active peptides have been used extensively for the analysis of either specificity or physiological significance of proteases. Hence, the hydrolysis of these substrates with proteinase yscA offers the opportunity for specificity comparisons with other aspartic proteinases. Three peptide hormones and derivatives hereof were chosen as substrates: angiotensin II, luteinizing hormone releasing hormone (LHRH), substance $P$, substance $P$ $\left(\mathrm{Tyr}^{8}\right)$ and substance $\mathrm{P}(6-11)$. The amino acid sequences of the peptide substrates and cleavage sites with proteinase ysc $\mathrm{A}$ and related aspartic proteinases are shown in Figure 4.

\subsubsection{Hydrolysis of angiotensin II}

Angiotensin II is an octapeptide hormone resulting from $\mathrm{C}$-terminal removal of the dipeptide -His-Leu from angiotensin I by the peptidase angiotensin-converting enzyme (ACE). Proteinase yscA slowly cleaved the $\mathrm{Tyr}^{4}-\mathrm{Ile}^{5}$ bond of angiotensin II. $55 \%$ was cleaved after 5 hours digestion at $\mathrm{E} / \mathrm{S}$-ratio $1 / 2,000,25^{\circ} \mathrm{C}$, and no other cleavages were observed. Calf chymosin and cathepsin D's isolated from human and rat brains are unable to cleave this substrate $(3,15)$, whereas fungal extracellular aspartic proteinases from Mucor, Irpex, Aspergillus and Endothia species cleave the same $\mathrm{Tyr}^{4}-\mathrm{Ile}^{5}$ bond of angiotensin II (or angiotensin I) $(12,15)$.

\subsubsection{Hydrolysis of luteinizing hormone- releasing hormone (LHRH)}

The decapeptide LHRH was highly resistant to the proteolytic activity of proteinase yscA. A small fraction, corresponding to approx. $2 \%$ of the substrate was, however, cleaved at the Tyr ${ }^{5}$ $\mathrm{Gly}^{6}$ bond when digestion at E/S-ratio $1 / 3,333$ was allowed to proceed for 20 hours at $27^{\circ} \mathrm{C}$.

Chymosin and Mucor miehei protease readily cleave this peptide bond in LHRH at E/S-ratio $1 / 1,700,3$ hours incubation, and the fungal

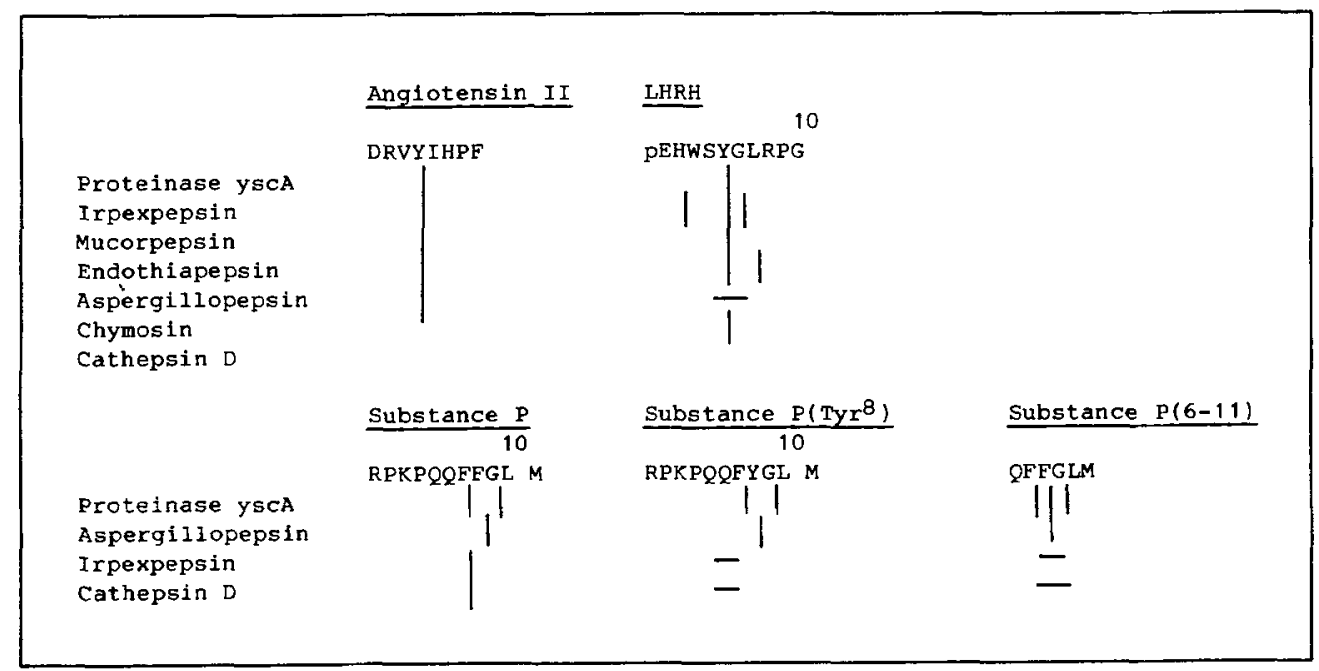

Figure 4. Hydrolyzed peptide bonds in peptide hormone substrates digested with proteinase yscA and related aspartic proteinases $(3,12,15)$. (-: no data found with the enzyme). 


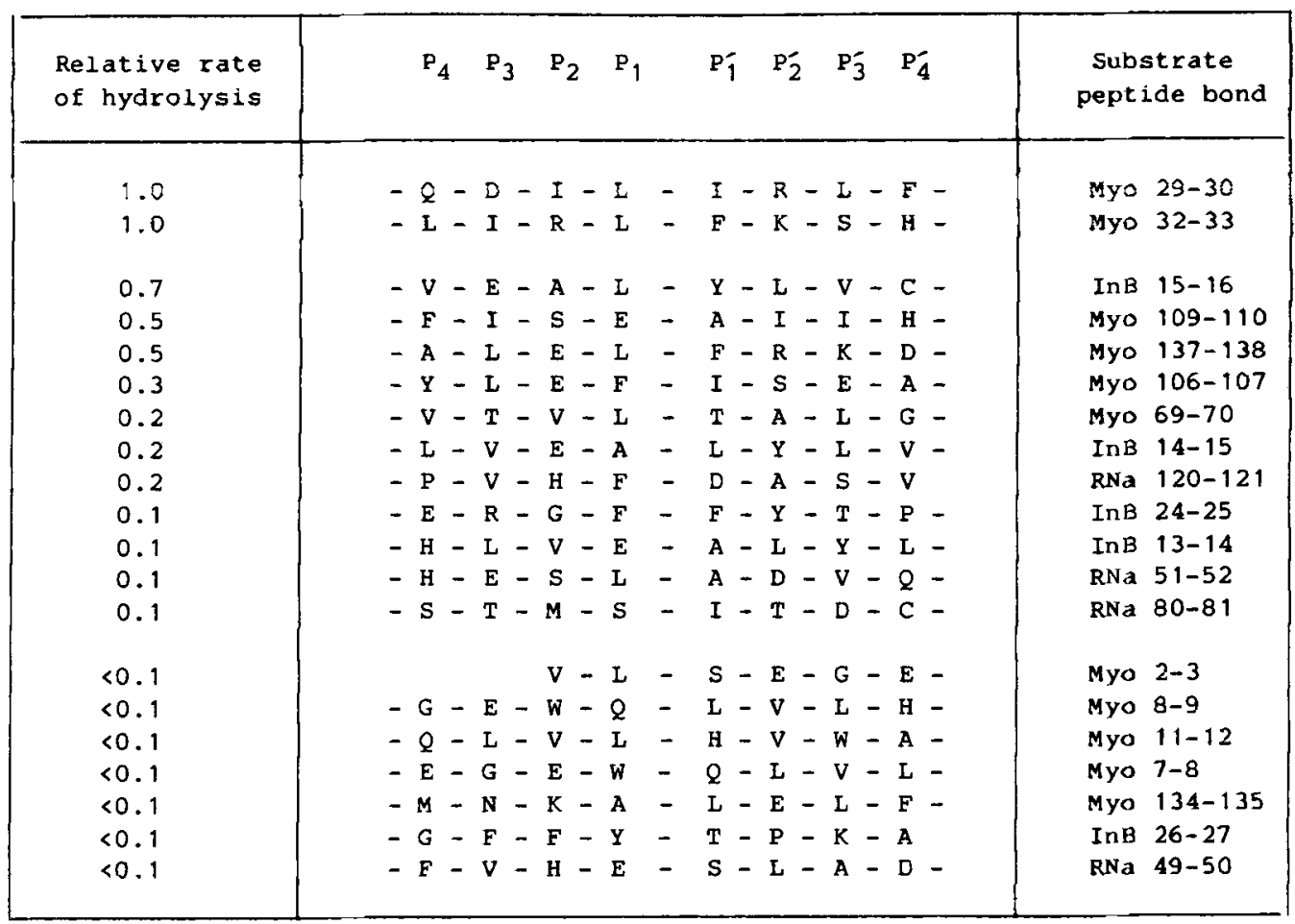

Figure 5. Peptide bonds in myoglobin (Myo), ox. insulin B-chain ( $\operatorname{MB}$ ) and ox. ribonuclease (RNa) cleaved by proteinase yscA. The relative rates of hydrolysis were estimated from quantitative amino acid analysis of recovered peptides after digestion for $60 \mathrm{~min}$ at E/S-ratio 1/2,350 and HPLC separation. Hydrolysis rates for insulin B-chain and ribonuclease, obtained at other conditions, were normalized to this $\mathrm{E} / \mathrm{S}$-rate and hydrolysis time.

aspartic proteinases from Irpex lacteus and Endothia parasitica also cleave this bond in addition to $\mathrm{His}^{2}-\mathrm{Trp}^{3}$, $\mathrm{Gly}^{6}-\mathrm{Leu}^{7}$ (I. lacteus) and Leu $^{7}-\operatorname{Arg}^{8}$ (E. parasitica) (15).

\subsubsection{Hydrolysis of substance $P$ and its derivatives}

Substance $P$ is an undecapeptide with a $\mathrm{Phe}^{\text {? }}$ $\mathrm{Phe}^{8}$ bond which would typically be subceptible to cleavage by an aspartic proteinase. This bond was, indeed, cleaved by proteinase yscA, in addition to the Gly'-Leu ${ }^{10}$ bond which was less labile. Two hours incubation at E/S-ratio 1/ 2,000 resulted in $38 \%$ molar conversion of substance Pinto peptides $\mathrm{Arg}^{1}-\mathrm{Phe}^{7}$ (30\%), $\mathrm{Arg}^{1}-$ Gly ${ }^{9}(8 \%)$ and $\mathrm{Phe}^{8}-\mathrm{Met}^{\prime \prime}$ (25\%). (Numbers in paranthesis are molar recoveries as percentage of mol substrate). Replacement of $\mathrm{Phe}^{8}$ with
$\mathrm{Tyr}^{8}$ slightly reduced the degree of conversion to $32 \%$, and the peptides generated were $\mathrm{Arg}^{1}-\mathrm{Phe}$ (15\%), $\operatorname{Arg}^{1}-\mathrm{Gly}^{9}(17 \%)$ and $\mathrm{Tyr}^{8}-\mathrm{Met}^{11}$ (14\%).

The N-terminally shortened hexapeptide substance $\mathrm{P}^{6-11}$ under the same conditions was converted $27 \%$ into peptides $\mathrm{Gln}^{6}-\mathrm{Phe}^{7}(8 \%)$, $\mathrm{Gln}^{6}-\mathrm{Phe}^{8}(11 \%)$ and $\mathrm{Gln}^{6}-\mathrm{Gly}^{9}(8 \%)$.

Brain cathepsin D and the Irpex lacteus proteinase also cleave the $\mathrm{Phe}^{7}-\mathrm{Phe}^{8}$ bond in substance $P(3,15)$ whereas the Aspergillus niger proteinase cleaves $\mathrm{Phe}^{8}-\mathrm{Gly}^{9}$ in substance $P$ and substance $P(6-11)$, and $\mathrm{Tyr}^{8}-\mathrm{Gly}^{9}$ in substance $P\left(\right.$ Tyr $\left.^{8}\right)(12)$.

\section{DISCUSSION}

The physiological role of proteinase yscA is controversial. In vitro studies performed in the 1970's suggested that several specific zymogen 
activations and enzyme deactivations (e.g. of chitin synthase and enzymes in the gluconeogenic pathway) depended on proteinase yscA (11), but later genetic studies with mutants devoid in proteinase yscA failed to corroborate these results (31). The enzyme was subsequently considered solely a catalyst of unspecific protein break-down, until it was shown that proteinase yscA also acts as a specific maturase for other vacuolar hydrolases $(2,32)$. How is the catalytic specificity designed to accomplish such diverse functions? The results of the present investigation show that the specificity of proteinase yscA towards denatured protein substrates resembles the specificity of pepsin (23) and particularly of cathepsin D (13), which also has a dual significance, since it is supposed to be involved in protein turnover in the cell as well as specific limited proteolysis associated with inflammatory and malignant processes $(10,16)$.
Figure 5 summarizes the observed cleavage positions in the three denatured protein substrates, and adjacent residues that may interact with the binding cleft are included. Figure 6 lists the occurrence of side chains in either $P_{1}$ or $P_{i}^{\prime}$ subsites (SCHECHTER and BERGER notation (26)) of the three substrates tested in this investigation.

It is obvious that proteinase yscA, like pepsin, prefers to cleave peptide bonds joining, mostly large, hydrophobic amino acids, though Ile is limited to $\mathrm{P}_{1}^{\prime}$. Figure 7 lists all the peptide bonds with favourable amino acid side chains in $\mathrm{P}_{1}$ (Leu or Phe) and in $\mathrm{P}_{1}^{\prime}$ (Phe or Ile) that are not cleaved by proteinase yscA, and it appears that basic side chains in $\mathrm{P}_{1}$ or $\mathrm{P}_{1}^{\prime}$ are prohibitive for cleavage by proteinase yscA in analogy with mammalian pepsin, chymosin and cathepsin $\mathrm{D}$. This is in contrast to the extracellular aspartic proteinases produced by the yeast Candida albi-

\begin{tabular}{|c|c|c|c|}
\hline $\begin{array}{l}\text { Amino acids } \\
\text { in } \mathrm{P}_{1} \text { or } \mathrm{P}_{1}^{\prime}\end{array}$ & $\begin{array}{l}\text { Number of peptide } \\
\text { bonds cleaved }\end{array}$ & $\begin{array}{l}\text { Total number of } \\
\text { peptide bonds }\end{array}$ & $\begin{array}{c}\text { Fraction of peptide } \\
\text { bonds cleaved }\end{array}$ \\
\hline \multicolumn{4}{|l|}{$P_{1}$} \\
\hline Leu & 8 & 24 & 0.33 \\
\hline Phe & 3 & 12 & 0.25 \\
\hline Giu & 3 & 21 & 0.15 \\
\hline Ala & 2 & 31 & 0.06 \\
\hline Tyr & 1 & 11 & 0.09 \\
\hline $\operatorname{Trp}$ & 1 & 2 & 0.50 \\
\hline Gln & 1 & 13 & 0.08 \\
\hline Ser & 1 & 22 & 0.05 \\
\hline \multicolumn{4}{|l|}{$\mathrm{P}_{1}^{-}$} \\
\hline Phe & 3 & 12 & 0.25 \\
\hline Ile & 3 & 12 & 0.25 \\
\hline Leu & 3 & 24 & 0.13 \\
\hline Ala & 3 & 31 & 0.10 \\
\hline Thr & 2 & 16 & 0.12 \\
\hline Ser & 2 & 22 & 0.09 \\
\hline Tyr & 1 & 11 & 0.09 \\
\hline Gln & 1 & 13 & 0.08 \\
\hline Asp & 1 & 11 & 0.09 \\
\hline $\mathrm{His}$ & 1 & 18 & 0.06 \\
\hline
\end{tabular}

Figure 6. Amino acids occupying substrate subsites $P_{1}$ or $P_{1}^{\prime}$ in peptide bonds of myoglobin, ox. insulin $B$-chain and ox. ribonuclease, that are cleaved by proteinase yscA. 


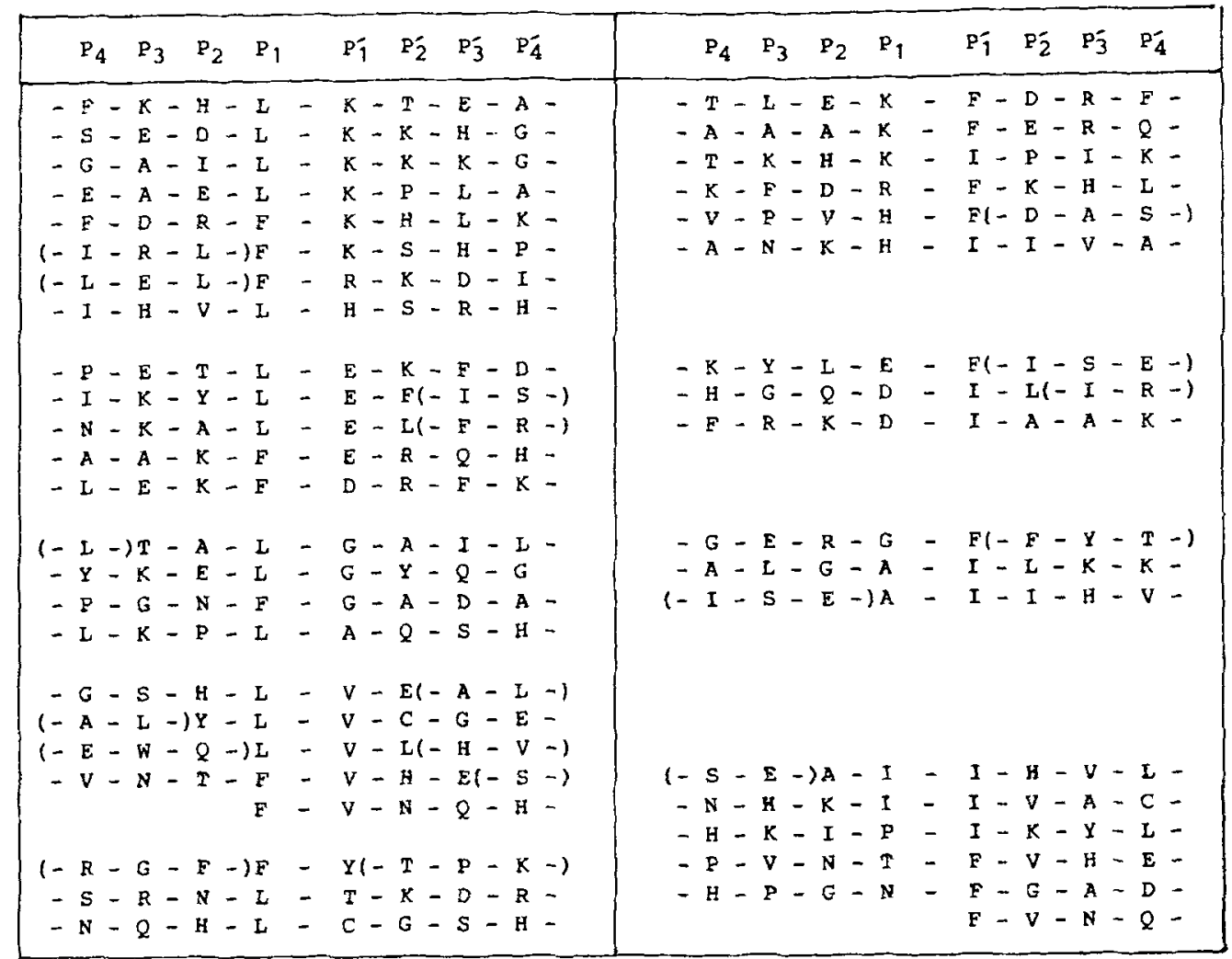

Figure 7. Peptide bonds in myoglobin, ox. insulin B-chain and ox, ribonuclease with Leu or $P$ he in $P$, (left column) or with Ile or Phe in $P_{i}^{\prime}$ (right column), that are not cleaved by proteinase yscA. Empty positions are due to the $N$ or C-termini of the substrate molecule and brackets enclose sequences cleaved off by proteinase yscA.

cans and by fungi belonging to Penicillium, Endothia, Aspergillus, Rhizopus, Irpex and Cladosporium genera $(12,14,15,24)$. These enzymes (but not Mucor rennin) exhibit a trypsin-like preference for a basic residue in the $P_{1}$-position of the substrate, and the enzymes from Endothia parasitica and Irpex lacteus moreover have been shown to accept arginine in the $P_{i}$ substrate subsite (15). The fungal extracellular enzymes also share a relative distant prima- ry structure homology with pepsin, cathepsin D and proteinase yscA (25\%-30\% sequence identity). Some fungi and Candida yeasts, however, in addition to the extracellular proteinases, have been shown to produce intracellular (vacuolar) aspartic proteinases, which have been far less characterized $(17,22)$. It is likely that these enzymes are pepsin-like and that they occur in all fungi, with similar physiological significance and biochemical properties as yeast vacuolar

Table I. Michaëlis-Menten parameters and specificity constants for the hydrolysis of myoglobin by proteinase yscA and porcine pepsin at $37^{\circ} \mathrm{C}$ in $0.05 \mathrm{M}$ ammonium formiate, and at pH 3.20 and 2.50 , respectively.

\begin{tabular}{|l|c|c|c|}
\hline & $K_{\mathrm{m}}(\mathrm{mM})$ & $k_{c a t}\left(\mathrm{sec}^{-1}\right)$ & $\left.k_{\mathrm{cat}} / x_{\mathrm{m}}(\mathrm{mM})^{-1} \mathrm{sec}^{-1}\right)$ \\
\hline Proteinase yscA & $0.08 \pm 0.01$ & $3.9 \pm 0.8$ & $50 \pm 5$ \\
Pepsin & $0.20 \pm 0.01$ & $8.2 \pm 3.0$ & $40 \pm 3$ \\
\hline
\end{tabular}


proteinase yscA and the mammalian lysosomal cathepsin D.

The acid Glu is frequently occurring in $P_{1}$, though Asp is disliked in this position (Fig. 7). Pepsin has a weak preference for both these residues in $P_{1}$ (23). Glu is not accepted in $P_{1}^{\prime}$, but one cleaved bond has an Asp in $\mathrm{P}_{1}^{\prime}$. Pepsin has a high preference for Glu in $\mathrm{P}_{2}$ which is apparently mirrored in proteinase yscA: 4 out of the 20 positions cleaved have a Glu in $\mathrm{P}_{2}$. A dislike for Lys and $\operatorname{Arg}$ in $\mathrm{P}_{3}$, as in pepsin (23), is probably the reason why $\mathrm{Leu}^{89}-\mathrm{Ala}^{90}$ in myoglobin and $\mathrm{Leu}^{35}-\mathrm{Thr}^{36}$ in oxidized ribonuclease are resistant to hydrolysis. There are, however, important differences between pepsin and proteinase yscA. Proteinase yscA dislikes peptide bonds with charged or small amino acid side chains in $\mathbf{P}_{1}^{\prime}$, (see Fig. 7) but Val is also prohibitive, whereas pepsin has a positive preference for Val in this position (23). Three peptide bonds in the protein substrates with Val in $\mathrm{P}_{1}^{\prime}$ are cleaved by pepsin but not by proteinase yscA ( $\mathrm{Leu}^{9}-\mathrm{Val}^{10}$ in myoglobin and $\mathrm{Phe}^{\mathrm{l}-\mathrm{Val}^{2}}$ and $\mathrm{Leu}^{11}-\mathrm{Val}^{12}$ in insulin B-chain). The $\mathrm{Tyr}^{16}$-Leu ${ }^{17}$ bond in insulin Bchain is cleaved by pepsin and cathepsin $D$, but not by proteinase yscA. This could result from a dislike for Tyr in $\mathrm{P}_{1}$, but more likely from a rapid removal of adjoining peptide segments (Phe ${ }^{1}-$ Leu $^{15}$ ), leaving too few amino acids for proper enzyme-substrate interactions at the $\mathrm{N}$ terminal side of $\mathrm{Tyr}^{16}{ }^{16}$ Leu $^{17}$.

Finally, an important difference is in the degree of hydrolysis of the substrates. The values of $\mathrm{k}_{\text {cat }} / \mathrm{K}_{\mathrm{m}}$ for hydrolysis of the first peptide bond in myoglobin by proteinase yscA and pepsin suggest a similar catalytic efficiency. Pepsin, however, cleaves $8.9 \%$ ( 27 bonds) of all peptide bonds in the three protein substrates (304 bonds), whereas proteinase yscA only cleaves $6.6 \%$ ( 20 bonds), indicating a narrower specificity. The numbers do not correspond to "terminal" cleavage, but refer to extensive digestions, for which the conditions are described in the Methods section. The statistical cleavage probability of a peptide bond by pepsin has been reported to be $15 \%$ after deepgoing digestion used during protein sequencing (23).

In insulin B-chain and myoglobin, cathepsin $D$ has been shown to cleave in 10 , or perhaps 11 , out of the 16 cleavage positions observed with proteinase yscA (13). The assignment of cleavage position $\mathrm{Ala}^{110}$-Ile ${ }^{111}$ in myoglobin with cathepsin $\mathrm{D}$ was based solely on amino acid analysis of the putative peptide Ile ${ }^{111}-\mathrm{Leu}^{137}$. The peptide $\mathrm{Ala}^{110}-\mathrm{Leu}^{137}$, resulting from hydrolysis with proteinase yscA, in our hands yielded ambigous values for Ala (between 6 and 7) by amino acid analysis. $\mathrm{N}$-terminal sequencing established $\mathrm{Ala}^{110}$ as the $\mathrm{N}$-terminal, and consequently $\mathrm{Glu}^{109}-\mathrm{Ala}^{110}$ as the cleaved bond, and this might also be the case with cathepsin D. The major difference between the substrate specificities of proteinase yscA and cathepsin D towards myoglobin and insulin B-chain is observed in the cleavage of the central hydrophobic sequence of insulin B-chain: Cathepsin D was reported not to cleave $\mathrm{Glu}^{13}-\mathrm{Ala}^{14}$ and $\mathrm{Ala}^{14}$. $\mathrm{Leu}^{15}$ as proteinase yscA and pepsin do. Except for the cleavage of $\mathrm{Glu}^{109}-\mathrm{Ala}^{110}$ ( or Ala ${ }^{110}-\mathrm{Il}^{111}$ ), cathepsin D exclusively cleaves after large hydrohobic amino acids in myoglobin and insulin B-chain.

The cleavage of peptide substrates by proteinase yscA resembles the cleavage pattern obtained with other aspartic proteinases. Proteinase yscA is, however, apparently more active against both angiotensin II and substance $P$ than cathepsin $D$, reflecting the observations using protein substrates.

The pepsin-like nature of proteinase yscA is in good agreement with one of the proposed functions of the vacuolar proteinases, which is general breakdown of excessive, aberrant and longlived proteins (28). Accordingly, proteinase yscA is responsible for normal yeast differentiation during sporulation induced by nutrient deficiency; a process involving highly elevated protein turnover $(1,28)$. The narrower specificities of proteinase ysc $A$ and cathepsin $D$, as compared to pepsin, might be essential for the role of these enzymes in limited proteolytic processes. AMMERER et al. (2) and WOOLFORD et al. (32) independently demonstrated that mutant yeast strains deficient in proteinase yscA accumulate inactive precursors of proteinase yscB, carboxypeptidase ysc $\mathrm{Y}$ and other vacuolar hydrolases, suggesting a regulatory role of proteinase yscA for the activity of these enzymes. The subsite-specificity of proteinase yscA does, however, not directly account for the 
observed dependence on proteinase yscA for hydrolase maturation in yeast $(2,19,32)$. The cleavages necessary for "correct" N-terminal processing of proteinase ysc $\mathrm{B}$, carboxypeptidase yscY $\mathrm{Y}$ and proteinase yscA itself, occur between amino acids with low cleavage probability by proteinase yscA: $\mathrm{Glu}^{-3}-\mathrm{Ala}^{-2}-\mathrm{Thr}^{-1}-\mathrm{Glu}^{1}-\mathrm{Phe}^{2}-$ $\mathrm{Asp}^{3}$ - in proteinase yscB (21), $-\mathrm{Arg}^{-3}-\mathrm{Val}^{-2}-\mathrm{Asn}^{-1}$ - Lys ${ }^{1}-\mathrm{Ile}^{2}-\mathrm{Lys}^{3}$ - in carboxypeptidase yscY (30) and $-\mathrm{Phe}^{-3}-\mathrm{Thr}^{-2}-\mathrm{Glu}^{-1}-\mathrm{Gly}^{1}-\mathrm{Gly}^{2}-\mathrm{His}^{3}-$ in proteinase yscA itself $(2,32)$. Maturation of the precursor of proteinase yscB additionally involves sequential removal of $\mathrm{C}$-terminal fragments, one of which is catalyzed by proteinase yscA (20). The exact position of the cleaved bond has not yet been established. Hydrolase maturations are multi-step limited proteolytic reactions, and proteinase yscA is most likely involved in cleavages leading to slightly higher molecular weight intermediates $(19,20)$. Such intermediates are catalytically active and might be physiologically important, although the proteinases obtained from cells at the end of growth and after extensive autoactivation of the cell lysate during enzyme purification have lower molecular weights.

\section{ACKNOWLEDGEMENTS}

I would like to thank MARTIN OTTESEN for encouragement, interest and stimulating discussions during this study and HANNE CHRISTIANSEN, Sidsel EHLers and BodIL CoRNELIUSSEN for their excellent technical assistance.

\section{REFERENCES}

1. ACHSTETTER, T \& D.H. WOLF: Proteinases, proteolysis and biological control in the yeast Saccharomyces cerevisiae. Yeast 1, 139-157 (1985)

2. Ammerer, G., C.P. Hunter, J.H. Rothman, G.C. SAARI, L.A. VAlLS \& T.H. Stevens: PEP4 gene of Saccharomyces cerevisiae encode proteinase $A$, a vacuolar enzyme required for processing of vacuolar precursors. Mol. Cell. Biol. 6, 2490-2499(1986)

3. AZaryan, A.V. \& A.A. Galoyan: Substrate specificity of cerebral cathepsin D and high-Mr-aspartic endopeptidase. J. Neurosci. Res. 19, 268271 (1988)
4. BREDDAM, K.: Chemically modified carboxypeptidase $Y$ with increased amidase activity. Carlsberg Res. Commun. 49, 535-554 (1984)

5. Craig, L.C., W. Konigsberg \& T.P. King: Peptide chain (A and B) from beef insulin. Biochem. Prep. 8, $70-75$ (1961)

6. DReyer, T., B. HALKIER, I.SvendSEN \& M. OtTesen: Primary structure of the aspartic proteinase A from Saccharomyces cerevisiae. Carlsberg Res. Commun. 51, 27-41 (1986)

7. Dunn, B.M., M. Jimenez, B.F. Parten, M.J. VALLER, C.E. ROLPH \& J.KAY: A systematic series of synthetic chromophoric substrates for aspartic proteinases. Biochem. J. 237, 899-906 (1986)

8. DunN, B.M., B. KammermanN \& K.R. MCCURRY: The synthesis, purification and evaluation of a chromophoric substrate for pepsin and other aspartyl proteases. Anal. Biochem. 138, 68-73(1984)

9. FRUTON, J.S.: The mechanism of the catalytic action of pepsin and related acid proteinases. Adv. Enzymol. 44, 1-36 (1976)

10. GreenbauM, L.M.: Cathepsin D-generated pharmacologically active peptides (leukokinins) and their role in ascites fluid accumulation. In: Proteases and Biological Control, Reich, E., Rifkin, D.B. \& Shaw, E. eds., CSH Lab. Press, pp. 223-228 (1975)

11. Holzer, H.: Catabolite inactivation in yeast. Trends in Biochem. Sci. 1, 178-181 (1976)

12. Ido, E., T. SaIto \& M. YamasakI: Substrate specificity of acid proteinase A from Aspergillus niger var. macrosporus. Agric. Biol. Chem. 51, 2855-2856 (1987)

13. Imoto, T., K. OKaZaKI, H. Koga \& H. Yamada: Specificity of rat liver cathepsin D. J. Biochem. (Tokyo) 101, 575-580 (1987)

14. Kobayashi, H., I. KusaKabe \& K. MuraKamI: Substrate specificity of the milkclotting enzyme from Irpex lacteus on $\alpha_{51}$-casein. Agric. Biol. Chem. 49, 1611-1619 (1985)

15. Kobayashi, H., I. KusaKabe, M. OKumura \& K. MURAKAMI: Substrate specificity of the milk-clotting enzyme from Irpex lacteus on peptide hormones. Agric. Biol. Chem. 50, 923-930 (1986)

16. MARKS, N., M. BENUCK \& G. HASHIM: Specificity of brain cathepsin $\mathrm{D}$ : Cleavage of model peptides containing the susceptible Phe-Phe region of myelin basic protein. J. Neurosci. Res. 5, 217-223 (1980)

17. Martinola, E., U. Heck, T. Boller, A. Wiemken \& P. MATILE: Some properties of vacuoles isolated from Neurospora crassa slime variant. Arch. Microbiol. 120, 31-34 (1979)

18. Matile, P. \& A. Wiemken: The vacuole as the lysosome of the yeast cell. Arch. Microbiol. 56, 
148-155 (1967)

19. MeChLER, B., H. MÜLleR \& D.H. Wol.F: Maturation of vacuolar (lysosomal) enzymes in yeast: Proteinase yscA and proteinase yscB are catalysts of the processing and activation event of carboxypeptidase yscY. EMBO J. 6, 2157-2163 (1987)

20. Moehle, C.M., C.K. Dixon \& E.W. Jones: Processing pathway for protease B of Saccharomyces cerevisiae. J. Cell. Biol. 108, 309-325 (1989)

21. Moehle, C.M., R. Tizard, S.K. Lemmon, J. Smart \& E.W. Jones: Protease B of the lysosome-like vacuole of the yeast Saccharomyces cerevisiae is homologous to the subtilisin family of serine proteases. Mol. Cell. Biol. 7, 4390-4399 (1987)

22. PORTILLO, F. \& C. GANCEDO: Purification and properties of 3 intracellular proteinases from Candida albicans. Biochim. Biophys. Acta 881, 229-235 (1986)

23. Powers, J.C., A.D. Harley \& D.V. MYers: Substrate specificity of porcine pepsin. In: Acid Proteases, Structure Function and Biology, Tang, J. ed., Plenum, New York pp. 141-158 (1977)

24. RÜCHEL, R., R. TEGeler, \& M. TROST: A comparison of secretory proteinases from different strains of Candida albicans. Sabouraudia 20, 233-244 (1982)

25. SANGER, F. \& H. TUPPY: The amino-acid sequence in the phenylalanyl chain of insulin. Biochem. J. 49, 481-490 (1951)
26. SCHECHTER, I. \& A. BERGER: On the size of the active site in proteases. Biochem. Biophys. Res. Commun. 27, 157-162 (1967)

27. SHewale, J.G. \& J. TANG: Amino acid sequence of porcine spleen cathepsin D. Proc. Natl. Acad. Sci. USA 81, 3703-3707 (1984)

28. Suarez-Rendueles, P. \& D.H. Wolf: Proteinase function in yeast: Biochemical and genetic approaches to a central mechanism of post-translational control in the eucaryote cell. FEMS Microbiology Reviews 54, 17-46 (1988)

29. TanG, J., P. Sepulveda, J. Marciniszyn, K.C.S Chen, W.-Y. Huang, N. TAO, D. LiU \& J.P. Lanier: Amino acid sequence of porcine pepsin. Proc. Natl. Acad. Sci. USA 70, 3437-3439 (1973)

30. Valls, L.A., C.P. Hunter, J.H. Rothman \& T.H STEVENS: Protein sorting in yeast: The localization determinant of yeast vacuolar carboxypeptidase $Y$ resides in the propeptide. Cell 48, 887-897 (1987)

31. WOLF, D.H.: Proteinase action in vitro versus proteinase function in vivo: Mutants shed light on intracellular proteolysis in yeast. Trends Biochem. Sci. 7, 35-37 (1982)

32. Woolford, C.A., L.B. Daniels, F.J. Park, E.W. JoNes, J.N.V. ARSDELl \& M.A. INNIS: The PEP4 gene encode an aspartyl protease implicated in the post-translational regulation of Saccharomyces cerevisiae vacuolar hydrolases. Mol. Cell. Biol. 6, 2500-2510 (1986)

Accepted by H. KLENOW 